\title{
Adsorption and desorption characteristics of N235 levextrel resin for the dilute $\mathrm{HCl}$ Solution
}

\author{
Zhou Jieying,Mao Zhenqiang,Xu Haibo,Li Liu,Wei Tingmin, Yang Youming * \\ School of metallurgy and chemical engineering, Jiangxi University of Science and Technology , \\ Ganzhou,341000,Jiangxi,China; \\ *yanguming@126.com
}

\begin{abstract}
Key words: Rare earth separation, N235 levextrel resin, Adsorption, Desorption, $\mathrm{HCl}$
Abstract: The low concentration of hydrochloric acid produced during the separation process of rare earth no saponification extraction is best available for recycling. The adsorption and desorption characteristics of $\mathrm{N} 235$ resin on dilute $\mathrm{HCl}$ solution were investigated by static adsorption method and dynamic adsorption method. The adsorption equilibrium constant, the saturated adsorption capacity of resin and its relationship with the initial $\mathrm{HCl}$ concentration were obtained by static adsorption experiment. The results of dynamic adsorption showed that the adsorption flow rate, the resin column height, the $\mathrm{HCl}$ concentration, the chloride concentration in the solution, the downstream flow/countercurrent mode would affect the resin equilibrium adsorption capacity; Besides, the maximum concentration of $\mathrm{HCl}$ solution obtained by the adsorption and desorption of $\mathrm{N} 235$ resin on dilute $\mathrm{HCl}$ solution is equal to the initial concentration of adsorbate, and has obvious "memory effect",and with the method of alkali absorption can reach the enrichment of hydrochloric acid at extreme dilute solution.
\end{abstract}

\section{Introduction}

Solvent extraction is the main method of rare earth separation, the phosphine 2-ethylhexyl phosphate 2-ethyl hexyl ester (HEH/EHP) or (2-ethylhexyl) di-phosphate ester (HDEHP) is commonly used as extractant. In order to improve the extraction capacity and stable extraction ratio, people usually using alkali (such as ammonia, sodium hydroxide, lime, etc.) for extraction agent saponification, but this process would produce salinity wastewater which would pollute the environment ${ }^{[1]}$. Some innovative researches are continuing on the issue of acidic wastewater or high salt wastewater during the process of rare earth extraction. Huang xiaowei et $\mathrm{al}^{[2,3]}$.have comthe $\mathrm{HEH} / \mathrm{EHP}$ with HDEHP on synergistic extraction and made full use of their respective advantages, which enhanced the extraction capacity under the HEH/EHP acid condition and the HDEHP stripping rate, solved the ammonia nitrogen wastewater problem which produced in the process of the rare earth

extraction and separation. This technology have been successfully applied to practical production. Subsequently the new technology of using magnesium bicarbonate solution as a liquid saponification agent and precipitant on rare earth extraction and separation process ${ }^{[4]}$, and recycling use of magnesium to avoid the discharge of high concentrations of magnesium salt wastewater, which helped to eliminate acid waste water pollution from the source. Using buffer solution to adjust the acid during the extraction process is a meaningful task ${ }^{[5]}$, but the reagent can not be recycled.Yang youming etal. based on the strong alkaline amine extractant Trioctylamine(N235) has a strong extraction capacity of $\mathrm{HCl}$, put forward a system of P507-N235 double solvent extraction system which can make the hydrogen ions released during the extraction process of the rare earth with the acidic phosphine extractant not enter the aqueous phase and remain in the organic phase,and through a lot of experiments verified that the system does not need saponification, has a good extraction and separation effect on rare earth ions, besides the composite organic phase 
structure is stable and can be recycled ${ }^{[6,7,8]}$, organic phase before recycling can strip the acid in the N235 by water, and this method has a good industrial application prospects. But the concentration of hydrochloric acid gained by stripping is quite light ${ }^{[9]}$, and it is difficult to be reused in the process of the rare earth extraction and separation.

Many disposal methods for $\mathrm{HCl}$ wastewater have been established: the evaporation concentration method avoided the emission of waste acid ${ }^{[10]}$, but it has high equipment investment and energy consumption; the $\mathrm{HCl}$ acid analytical method ${ }^{[11]}$ can obtain high-purity $\mathrm{HCl}$,but it is only applicable for $28 \%-32 \%$ of waste hydrochloric acid ${ }^{[12]}$; the electrolytic method can attain cyclic utilization of resources, but it has high electricity consumption ${ }^{[13]}$; and the diffusion dialysis method can separate $\mathrm{HCl}$ from $\mathrm{HCl}$-bearing wastewater at low energy consumption and operation cost, but it has high equipment investment, low daily processing capacity per unit membrane area ${ }^{[14]}$, Tang Jianjun et al. ${ }^{[15]}$ studied the feasibility of recovering hydrochloric acid from rare earth chloride solution by vacuum membrane distillation. It was proved that vacuum distillation could recover up to $80 \%$ of free hydrochloric acid in rare earth chloride solution, but not dilute hydrochloric acid ,especially the dilute hydrochloric acid solution.

Levextrel resin, environment-friendly, low cost, high selectivity, is a new convenient and efficient separation resin ${ }^{[16]}$, we synthesized the $\mathrm{N} 235$ into the levextrel resin which can adsorption of dilute $\mathrm{HCl}$ solution and not easy to flow away.The $\mathrm{HCl}$ adsorption/desorption law of $\mathrm{N} 235$ levextrel resin was discussed in this paper, expect to solve the problem of saponification or acidic wastewater during the process of rare earth extraction.

\section{Experiment}

\section{Experimental reagents}

The experimental reagents include concentrated $\mathrm{HCl}$ acid (HR), lanthanum chloride solution (99.99\%), and N235 levextrel resin (20-40 meshes).

\section{Experimental instruments}

The main experimental apparatus is shown in Fig. 1.

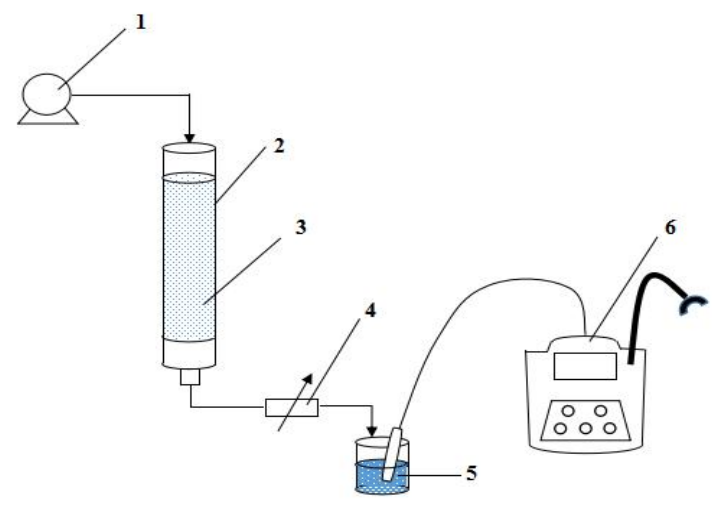

Fig.1 Main experimental apparatus

1- YZ15 peristaltic pump; 2- $\Phi 30 \mathrm{~mm} * 1000-\mathrm{mm}$ organic glass column (homemade); 3- N235 resin; 4- stop valve; 5- effluent; 6ST3100 pH agent

\section{Experimental method}

\section{Static experiment}

An $\mathrm{HCl}$ solution of $\mathrm{pH}=2.13$ with a certain amount of concentrated $\mathrm{HCl}$ acid and deionized water was prepared. Next, $100 \mathrm{ml}$ of the prepared $\mathrm{HCl}$ solution and a certain amount of levextrel resin were placed in a 500-ml beaker, which was vibrated for $2 \mathrm{~h}$ under $40{ }^{\circ} \mathrm{C}$. Some filtrate was collected for $\mathrm{pH}$ test. 
The complex $\mathrm{n}_{\mathrm{N} 235}: \mathrm{n}_{\mathrm{HCl}}=1: 1$ is often produced during $\mathrm{HCl}$ extraction of $\mathrm{N} 235$ levextrel $\operatorname{resin}^{[16]}$, thus:

$$
\begin{aligned}
& \overline{\mathrm{N} 235}+\mathrm{H}^{+}+\mathrm{Cl}^{-} \longrightarrow \overline{\mathrm{N} 235 \cdot \mathrm{HCl}} \\
& K=\frac{[\overline{\mathrm{N} 235 \cdot \mathrm{HCl}}]}{[\overline{\mathrm{N} 235}] \cdot\left[\mathrm{H}^{+}\right]\left[\mathrm{Cl}^{-}\right]}
\end{aligned}
$$

where $K$ is a chemical reaction constant and the rest are concentrations in $\mathrm{mol} / \mathrm{L}$ or $\mathrm{mol} / \mathrm{Kg}$.

\section{Dynamic experiment}

\section{Adsorption elution curve}

A certain amount of $\mathrm{N} 235$ resin column was taken, and a certain concentration of $\mathrm{HCl}$ acid solution was prepared. The peristaltic pump and the stop valve were opened to ensure that the raw material solution will pass through the ion exchange column at a constant flow rate. A beaker was placed at an outlet and every $100 \mathrm{ml}$ of sample was collected to test the acid concentration; data were recorded. The equilibrium adsorption of the resin was achieved when the acid concentration of the effluent was equal to that of the raw material solution. The experiment and test were stopped, and the concentration of the effluent was calculated. The $\mathrm{HCl}$ adsorption elution curve of $\mathrm{N} 235$ resin was drawn.

\section{Desorption elution curve}

After achieving the equilibrium adsorption of resin through the above operations, the stop valve was opened for half an hour to eliminate water. The raw material solution was changed by deionized water. The peristaltic pump was opened to ensure that the deionized water will pass through the ion exchange column at a constant flow rate. A beaker was placed in an outlet, and every $100 \mathrm{ml}$ of sample was collected to test the acid concentration; data were recorded. When the acid concentration of the effluent was $0.2 \%$ lower than that of the raw material solution, the desorption of resin was considered complete; the experiment was then stopped, and the $\mathrm{HCl}$ desorption elution curve of N235 resin was drawn.

\section{Results and discussion}

\section{Influencing factors of the adsorption process of resin}

\section{Influence of the adsorption solution flow rate on the adsorption effect of resin}

A cocurrent adsorption experiment was conducted with $15 \mathrm{~g}$ of resin, raw material solution $\mathrm{pH}$ of 1.76 , and under two flow rates $(14.5$ and $3.5 \mathrm{ml} / \mathrm{min})$. The $\mathrm{pH}$ test was conducted for every 100 $\mathrm{ml}$ of sample. The experiment was stopped after the resin equilibrium adsorption was achieved, and data were organized to draw the adsorption elution curve. The experimental results are shown in Fig. 2.

Fig. 2 shows that the higher flow rate results in the early achievement of resin equilibrium adsorption. The equilibrium adsorption was achieved at $500 \mathrm{ml}$ of effluent under a flow rate of 14.5 $\mathrm{ml} / \mathrm{min}$, and the resin equilibrium adsorption capacity was $0.3041 \mathrm{~mol} / \mathrm{kg}$. The equilibrium adsorption was achieved at $900 \mathrm{ml}$ of effluent under a flow rate of $3.5 \mathrm{ml} / \mathrm{min}$, and the resin equilibrium adsorption capacity was $0.5192 \mathrm{~mol} / \mathrm{kg}$. 


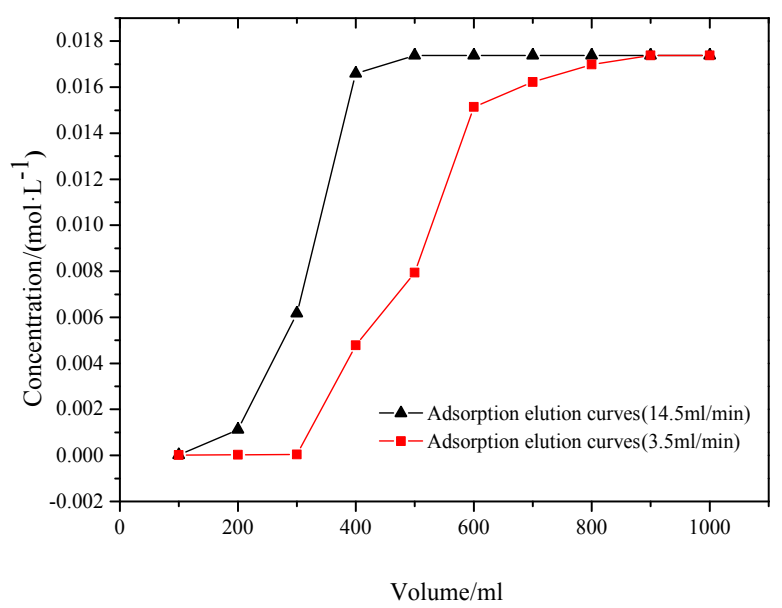

Fig.2 Adsorption elution curves under different adsorption solution flow rates

Therefore, the flow rate is negatively correlated with the adsorption capacity of resin. At similar conditions, the adsorption capacity of resin under a flow rate of $3.5 \mathrm{ml} / \mathrm{min}$ was $70.72 \%$ higher than that under $14.5 \mathrm{ml} / \mathrm{min}$. Thus, a higher flow rate can shorten the interaction time between the resin and the solution, deteriorate diffusion effect, and decrease the resin equilibrium adsorption capacity.

\section{Influence of the adsorption solution concentration on the adsorption effect of resin}

A cocurrent adsorption experiment was conducted with $15 \mathrm{~g}$ of resin, under a flow rate of 14.5 $\mathrm{ml} / \mathrm{min}$, and at different $\mathrm{pH}$ conditions (1.76 and 2.71). The $\mathrm{pH}$ test was conducted for every $100 \mathrm{ml}$ of sample; the experiment was stopped after the equilibrium adsorption of resin, and data were organized to draw the adsorption elution curve. The experimental results are shown in Fig. 3.

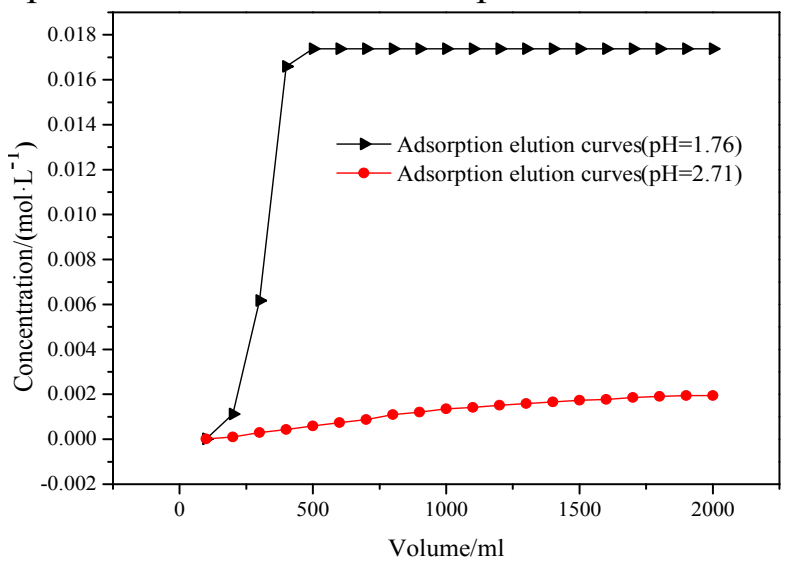

Fig.3 Adsorption elution curves under different $\mathrm{pH}$ conditions

Fig. 3 shows that the higher acid concentration of the adsorption solution can accelerate the achievement of the resin adsorption equilibrium. The equilibrium adsorption was achieved at 500 $\mathrm{ml}$ of effluent when $\mathrm{pH}=1.76$. However, at $\mathrm{pH}=2.71$, the equilibrium adsorption was not achieved until the amount of effluent reached $1800 \mathrm{ml}$, and the adsorption capacity of resin was 0.0996 $\mathrm{mol} / \mathrm{kg}$. In addition, a higher acid concentration could increase the resin equilibrium adsorption capacity. The equilibrium adsorption capacity of resin increased by $205.4 \%$ when $\mathrm{pH}$ decreased from 2.71 to 1.76 , indicating the significant influence of $\mathrm{pH}$ on the adsorption effect of resin. The reason was that a higher acid concentration of adsorption solution meant a higher concentration of $\mathrm{H}^{+}$and $\mathrm{Cl}^{-}$, thereby creating an environment conducive for adsorption reaction.

\section{Influence of rare-earth chloride concentration on the adsorption effect of resin}

Cocurrent adsorption experiments with and without lanthanum chloride $(0.0621 \mathrm{~mol} / \mathrm{L})$ were conducted with $15 \mathrm{~g}$ of resin, $\mathrm{pH}=1.76$, and flow rate of $14.5 \mathrm{ml} / \mathrm{min}$. The $\mathrm{pH}$ test was conducted for every $100 \mathrm{ml}$ of sample; the experiment was stopped after the equilibrium adsorption of resin was achieved. The experimental results are shown in Fig. 4. 


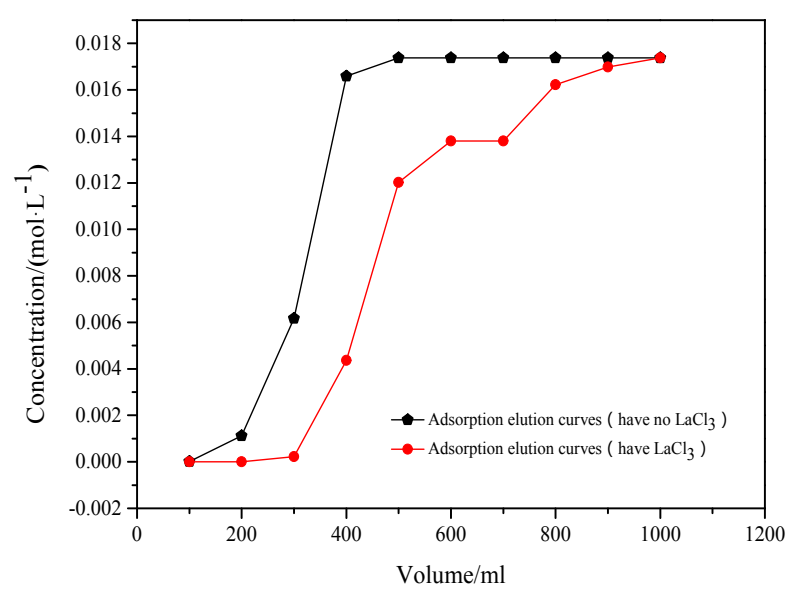

Fig.4 Adsorption elution curves with/without lanthanum chloride

According to the experimental results, the existence of rare-earth chloride will delay the achievement of the adsorption equilibrium of resin. The equilibrium adsorption was achieved at 500 $\mathrm{ml}$ of effluent when no lanthanum chloride was added into the adsorption solution; however, when lanthanum chloride was added, equilibrium adsorption was delayed to $1,000 \mathrm{ml}$ of effluent. The adsorption capacity of resin was $0.5265 \mathrm{~mol} / \mathrm{kg}$. However, when lanthanum chloride was added, the adsorption capacity of resin $(0.0621 \mathrm{~mol} / \mathrm{L})$ was $73.1 \%$ higher than that without lanthanum chloride.

This observation is attributed to the ability of lanthanum chloride to increase $\mathrm{Cl}^{-}$concentration in the water phase. According to Eq. 1, the higher $\mathrm{Cl}^{-}$concentration in the water phase is conducive for adsorption reaction, thus increasing the equilibrium adsorption capacity of resin.

\section{Influence of adsorption mode on the adsorption effect of resin}

Cocurrent and countercurrent adsorption experiments were performed with $15 \mathrm{~g}$ of resin, $\mathrm{pH}=2.71$, and under a flow rate of $14.5 \mathrm{ml} / \mathrm{min}$. The $\mathrm{pH}$ test was conducted for every $100 \mathrm{ml}$ of sample; the experiment was stopped after the equilibrium adsorption of resin was achieved. Experimental results are shown in Fig. 5.

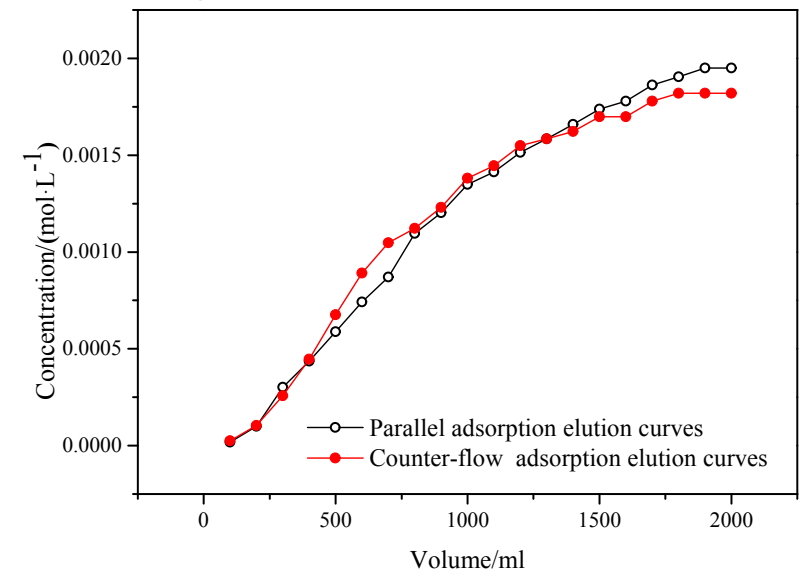

Fig.5. Adsorption elution curves under different adsorption modes

Results showed that the elution curves under parallel adsorption and counterflow adsorption are similar. The adsorption capacity of resin under the counterflow adsorption was $0.1046 \mathrm{~mol} / \mathrm{kg}$, which is $5 \%$ higher than that under parallel adsorption. Some fixed channels exist in the resin. During the parallel adsorption, the adsorption liquid exhibited only the effect of gravity and flows downward naturally from the resin, resulting in inadequate adsorption. During the counterflow adsorption, the adsorption solution exhibited the effect of gravity and an upward thrust, increasing the turbulence of the adsorption flow. Thus, the adsorption solution interacts with the resin more adequately, obtaining better adsorption effect.

\section{Influence of the aspect ratio of resin column on the adsorption effect of resin}

A cocurrent adsorption experiment was carried out under $\mathrm{pH}=1.76$, flow rate of $14.5 \mathrm{ml} / \mathrm{min}$, and $160 \mathrm{~g}$ of resin column. The $\mathrm{pH}$ test was conducted for every $500 \mathrm{ml}$ of sample. The experimental results were compared with those using $15 \mathrm{~g}$ of resin. The results are shown in Fig. 6. 


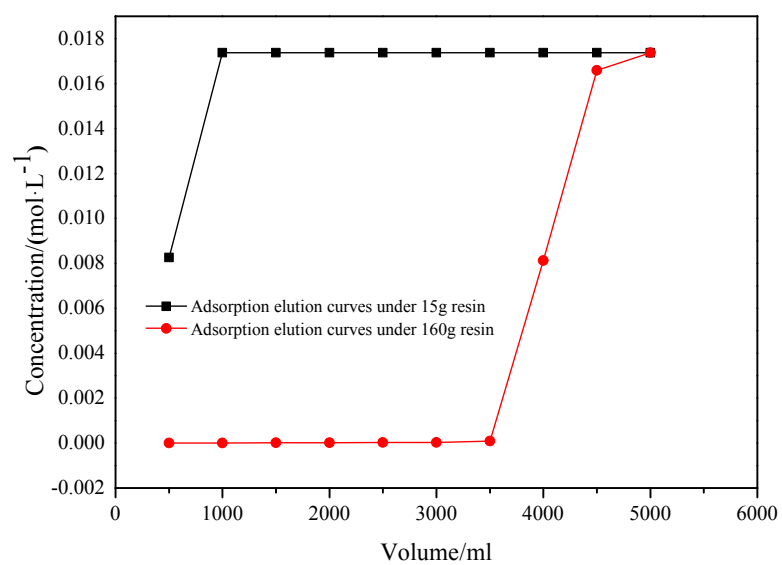

Fig.6 Adsorption elution curves under different aspect ratios of resin column

According to the experimental results, the higher resin dosage will delay the adsorption equilibrium. The adsorption equilibrium was achieved at $500 \mathrm{ml}$ of effluent with $15 \mathrm{~g}$ of resin; however, with $160 \mathrm{~g}$ of resin, the adsorption equilibrium was delayed to 5,000 $\mathrm{ml}$ of effluent, and the adsorption capacity of resin was $0.4109 \mathrm{~mol} / \mathrm{kg}$. A higher resin dosage resulted in the higher adsorption capacity of resin. The adsorption capacity using $160 \mathrm{~g}$ of resin was $35.1 \%$ higher than that using $15 \mathrm{~g}$ of resin; this is because the higher resin dosage increases the height of the resin column, which increases interaction time of the resin with $\mathrm{HCl}$, creating an environment conducive to an adequate $\mathrm{HCl}$ adsorption of resin, and thus delaying the adsorption equilibrium. Meanwhile, the diameter of the resin column was fixed and a taller column could reduce the proportion of invalid adsorption region, increasing the adsorption capacity of resin.

Influencing factors of resin desorption process

Influence of the adsorption solution concentration on adsorption and desorption elution curves

Four adsorption/desorption experiments were carried out with $10 \mathrm{~g}$ of resin and under a flow rate of $20 \mathrm{ml} / \mathrm{min}$; the $\mathrm{pH}$ values were $3,2.6,2.2$, and 1.8.In the experiments, the $\mathrm{pH}$ tests were conducted for every $100 \mathrm{ml}$ of sample. The adsorption continued after 20 test points to ensure adsorption equilibrium. Next, the desorption experiments were implemented. The first test point was $10 \mathrm{ml}$, and then $\mathrm{pH}$ test was conducted for every $100 \mathrm{ml}$ of sample. A total of 21 data were recorded. Results are shown in Fig. 7.

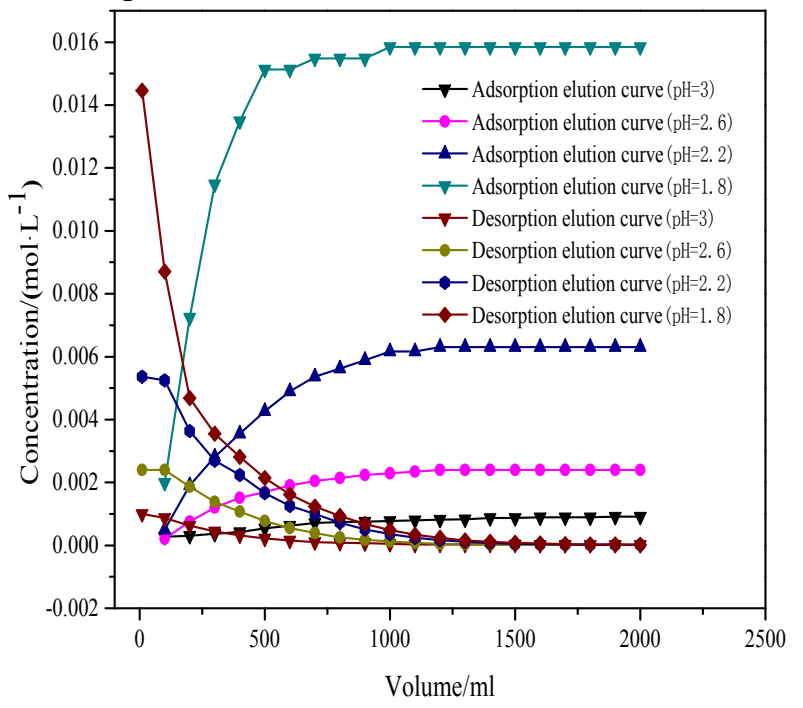

Fig.7 Influence of $\mathrm{pH}$ on the adsorption and desorption elution curves

Fig. 7 shows that:The $\mathrm{HCl}$ adsorption and desorption elution curves of the N235 resin were symmetric about the $\mathrm{x}$-axis, indicating that the concentration of the adsorption effluent increased quickly initially and then equilibrated slowly, whereas the concentration of desorption effluent dropped dramatically and then equilibrated gradually. This observation reflects that $\mathrm{HCl}$ desorption of $\mathrm{N} 235$ resin is the inverse process of adsorption and that the $\mathrm{HCl}$ desorption is easy and complete. 
The peak concentration of desorption effluent was close to the initial concentration of the adsorption effluent, indicating that the concentration of $\mathrm{HCl}$ desorption effluent in $\mathrm{N} 235$ resin exhibits a "memory effect". The adsorption and desorption elution curves of the same adsorption solution had one point of intersection. The higher the adsorption solution concentration, the higher the vertical coordinate (concentration) of this point of intersection, which is close to half concentration of the adsorption solution. Therefore, this point can be called as the "half-declining point" of desorption effluent concentration. The horizontal coordinate of this "half-declining point" was negatively correlated with the adsorption solution concentration, indicating that it took a shorter time (volume) for desorption effluent to reach the "half-declining point" when the adsorption solution concentration was higher. In other words, the higher the adsorption solution concentration, the quicker the concentration reduction during desorption will be.

Influence of the aspect ratio of resin column on the adsorption and desorption elution curves

Three adsorption/desorption experiments were carried out under a flow rate of $20 \mathrm{ml} / \mathrm{min}$ and $\mathrm{pH}=1.8$, in which the resin dosages were 10,20 , and $40 \mathrm{~g}$. The $\mathrm{pH}$ test was conducted for every 100 $\mathrm{ml}$ of sample until the achievement of the resin adsorption equilibrium. Next, desorption experiments were performed. Results are presented in Fig. 8.

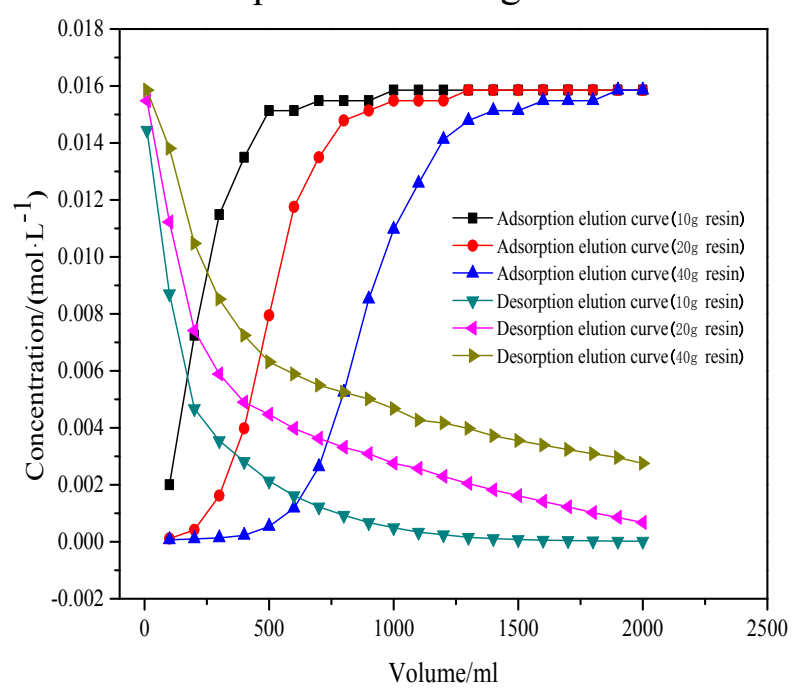

Fig.8 Adsorption and desorption elution curves under different resin dosages

Fig. 8 shows that:With the increase of resin dosage, the symmetry of adsorption and desorption elution curves about the $\mathrm{x}$-axis still existed, but was weakened to some extent. The maximum concentration of desorption effluent was still equal to or slightly lower than the initial concentration of the adsorption solution. The "memory effect" of the desorption effluent concentration exists. With the increase of resin dosage, the horizontal axis of the "half-declining point" increased, and it took a longer time for desorption effluent to reach this point. In other words, the higher resin dosage would slow down the concentration reduction of the desorption effluent.The highest concentration of desorption effluent was close to the initial concentration of the adsorption solution.

\section{The effect of chloride concentration on desorption and adsorption outflow curve}

Pack with $50 \mathrm{~g}$ resin and control the flow rate at $20 \mathrm{ml} / \mathrm{min}$. The concentration of $\mathrm{HCl}$ in the liquid was $0.050175 \mathrm{~mol} / \mathrm{L}$, and the $\mathrm{LaCl}_{3}$ in adsorption and desorption experiments was $2.63 \times 10^{-3}$, $9.805 \times 10^{-3}, 2.678 \times 10^{-3} \mathrm{~mol} / \mathrm{L}$, respectively. Each test of the $\mathrm{pH}$ was every $50 \mathrm{ml}$ until the adsorption process arrive a balance, while the desorption experiments set the first point at $5 \mathrm{ml}$, then test the $\mathrm{pH}$ at every $50 \mathrm{ml}$ until the $\mathrm{pH}$ remains the same. The result are shown in Fig. 9. 


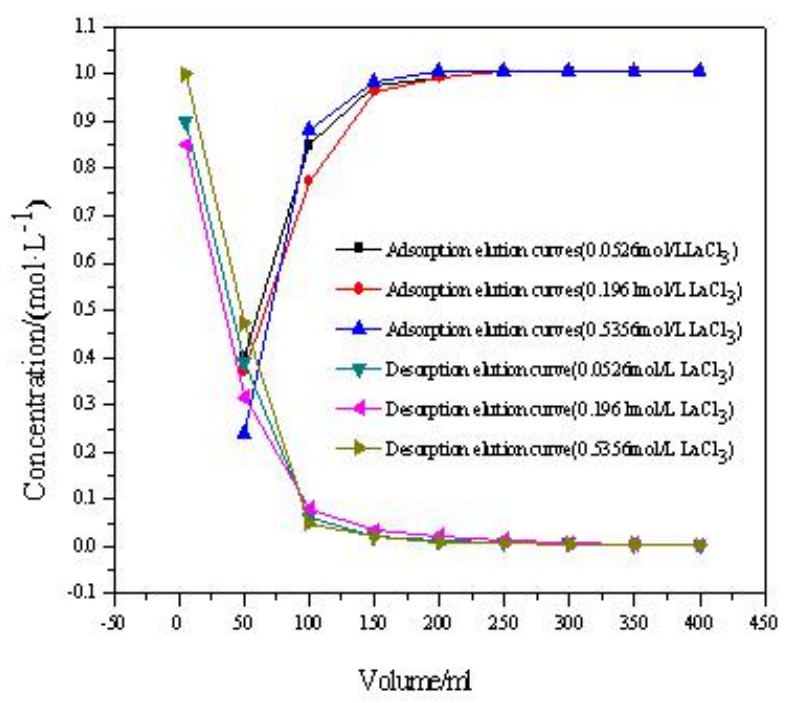

Fig. 9 Adsorption and desorption outflow curve at different lanthanum chloride concentration

It can be seen from Fig. 9 that with the concentration increase of lanthanum chloride in the solution, the $\mathrm{X}$-axis symmetry characteristic of the adsorption and desorption effluent curve still exists and didn't change. The highest concentration of desorption solution exists a "memory effect" phenomenon can still equal or slightly smaller than the adsorption liquid, which indicates that change the concentration of chloride (salt) solution can't increase the concentration of hydrochloric acid, but with the increase of the concentration of lanthanum chloride, the resin can reach a adsorption- desorption balance more quickly.

\section{Adsorption equilibrium constant of $\mathbf{N 2 3 5}$ resin and acid concentration of desorption effluent}

\section{Saturated adsorption capacity of $\mathbf{N 2 3 5}$ resin}

Accurate $20 \mathrm{~g}$ of resin was placed in $1-8^{\#} 500 \mathrm{ml}$ beakers in which $250-\mathrm{ml} \mathrm{HCL}$ solutions of different concentrations $(1.426,2.202,2.852,3.55,3.959,4.909,6.126$, and $6.908 \mathrm{~mol} / \mathrm{L})$ were added. Six hours of soaking adsorption was conducted at room temperature. The solution was filtered and the $\mathrm{HCl}$ concentration of the filtrate was determined. The adsorption capacity of resin could be deduced from:

$$
c_{n}=\frac{\left(c_{0}-c_{e}\right) * v}{m} * 1000
$$

where $c_{n}$ is adsorption capacity of resin $(\mathrm{mol} / \mathrm{kg}) ; c_{o}$ is the initial $\mathrm{HCl}$ concentration $(\mathrm{mol} / \mathrm{L}), c_{e}$ is the $\mathrm{HCl}$ equilibrium concentration $(\mathrm{mol} / \mathrm{L}), v$ is the volume $(\mathrm{L})$, and $m$ is the resin mass $(\mathrm{g})$.

The relation curve between $c_{n}$ and $c_{0}$ is shown in Fig. 10.

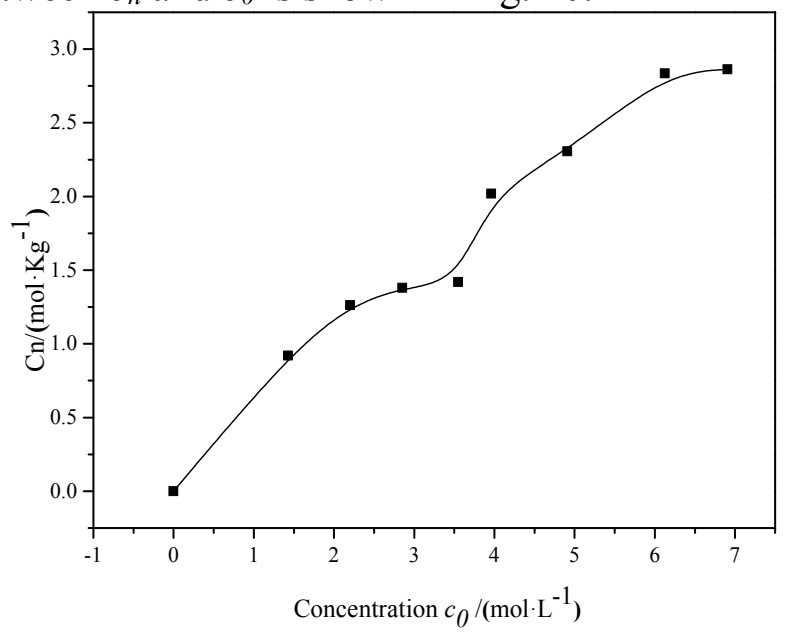

Fig.10elation curve between $c_{n}$ and $c_{0}$

Fig. 10 shows a positive relationship between $c_{n}$ and $c_{0}$ as well as two platforms. $c_{n}$ achieves 
the first stability when $c_{0}=3.55 \mathrm{~mol} / \mathrm{L}$, reaching $1.42 \mathrm{~mol} / \mathrm{kg} . c_{n}$ achieves the first stability when $c_{0}=6.126 \mathrm{~mol} / \mathrm{L}$, reaching $2.84 \mathrm{~mol} / \mathrm{kg}$. These results are similar with reference literature ${ }^{[17]}$. When $c_{0}$ was within the $\mathrm{pH}$ range, the saturated adsorption capacity of $\mathrm{N} 235$ resin was $1.42 \mathrm{~mol} / \mathrm{kg}$.

When the initial $\mathrm{HCl}$ concentration is in the $\mathrm{pH}$ range, the saturated adsorption capacity of $\mathrm{N} 235$ resin was $1.42 \mathrm{~mol} / \mathrm{kg}$.

\section{Adsorption equilibrium coefficient of $\mathbf{N} 235$ resin (K)}

Accurate $100 \mathrm{ml}$ of $\mathrm{HCl}$ solution $(\mathrm{pH}=2.13)$ was placed in beakers with $0.2,0.4,0.6,0.8$, and $1.0 \mathrm{~g} \mathrm{~N} 235 \mathrm{resin}$. The mixtures were stirred for $2 \mathrm{~h}$ under $40{ }^{\circ} \mathrm{C}$ for static adsorption experiments.

The above experimental data were analyzed according to Eq. 2, and $K$ was calculated. The relation curve of lgk and resin dosage $(\mathrm{m}(\mathrm{g}))$ is shown in Fig. 11.

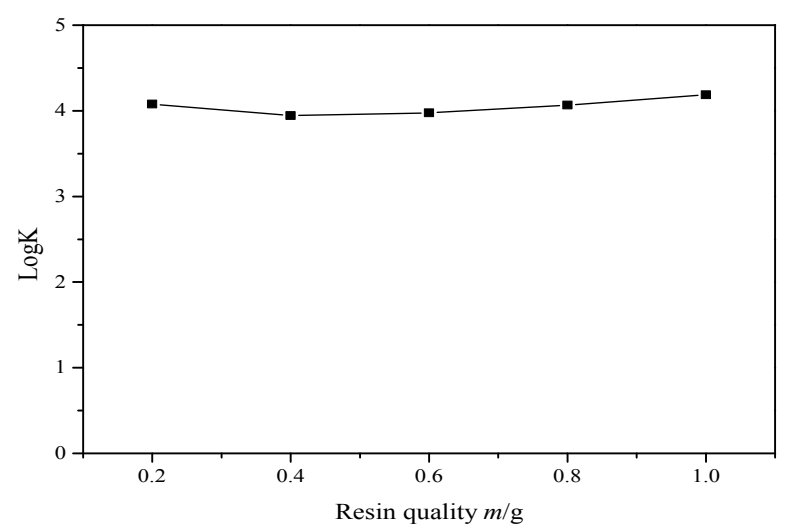

Fig.11 Relation curve of lgk and resin dosage

Fig. 11 shows that lgk fluctuated in a small range with resin dosage, averaging at $\operatorname{lgk}=4$, $k=1 \times 10^{4}$. Therefore, $K$ was considerably higher than 1 , and the adsorption was extremely easy. Under similar conditions, the adsorption process is priori to desorption process.

\section{Relationship between $\mathrm{HCl}$ concentration of desorption effluent and initial $\mathrm{HCl}$ concentration of the adsorption solution}

According to Eq. 2,

$$
\mathrm{Cn}=\mathrm{K} \cdot[\mathrm{N} 235] \cdot\left[\mathrm{H}^{+}\right] \cdot\left[\mathrm{Cl}^{-}\right]
$$

When the $\mathrm{HCl}$ concentration of adsorption effluent reaches the initial $\mathrm{HCl}$ concentration of the adsorption solution $\left(\left[\mathrm{H}^{+}\right]_{0},\left[\mathrm{Cl}^{-}\right]_{0}\right), \mathrm{HCl}$ concentration on $\mathrm{N} 235$ resin reaches the peak $\left(\mathrm{C}_{\mathrm{nmax}}\right)$,

$\mathrm{Cnmax}=\mathrm{K} \cdot[\mathrm{N} 235] \cdot\left[\mathrm{H}^{+}\right]_{0} \bullet\left[\mathrm{Cl}^{-}\right]_{0}$

If the desorption equilibrium constant is $K^{\prime}, \mathrm{HCl}$ concentration in desorption effluent $\left(\left[\mathrm{H}^{+}\right]_{\text {desorption, }}\left[\mathrm{Cl}^{-}\right]_{\text {desorption }}\right)$ is:

$\mathrm{K}^{\prime}=[\mathrm{N} 235] \cdot\left[\mathrm{H}^{+}\right]_{\text {desorption }} \cdot\left[\mathrm{Cl}^{-}\right]_{\text {desorption }} / \mathrm{Cn}$

$\left[\mathrm{H}^{+}\right]_{\text {desorption }} \cdot\left[\mathrm{Cl}^{-}\right]_{\text {desorption }}=\mathrm{K}^{\prime} \cdot \mathrm{Cn} /[\mathrm{N} 235]$

Since $\mathrm{K}^{*} \mathrm{~K}=1$, when no ion is added in the desorption effluent, $\left[\mathrm{H}^{+}\right]_{\text {desorption max }}$ corresponding to $\mathrm{C}_{\mathrm{nmax}}$ could be calculated by combining Eq. 5 , Eq. 6 and Eq. 7:

$\left[\mathrm{H}^{+}\right]_{\text {desorption } \max }=\left[\mathrm{H}^{+}\right]_{0}$

Eq. 8 reveals that $\left[\mathrm{H}^{+}\right]_{\text {desorption } \max } \leq \mathrm{C}_{\mathrm{n} \text { max }}$, which has been proven by the above experimental results. This means that even if the diameter ratio of adsorption desorption column is increased, the maximum concentration of hydrochloric acid in pure water desorption will not exceed the initial concentration of the adsorbed solution.

\section{Preparation of concentrated ammonium chloride solution by ammonia desorption}

The former result has been confirmed that the water desorption can't reach the purpose of concentrating the dilute hydrochloric acid, so instead by the ammonium water as a desorption reagent to reach the effect of neutralize the absorbed hydrochloric acid and the enrichment of extremely dilute hydrochloric acid.

Pack with 20 grams resin, and confecting the concentration of hydrochloric acid solution at 
$0.13,0.23,0.36 \mathrm{~mol} / \mathrm{L}$ respectively, and through the downstream adsorption method at a $10 \mathrm{ml} / \mathrm{min}$ flow rate. When the effluent concentration of hydrochloric acid was equal to the adsorption solution, which can consider the absorption-desorption had reached a balance, close the peristaltic pump and wait until the solution has been exhausted. Then using the concentration of ammonium water at $0.27 \mathrm{~mol} / \mathrm{L}$ to desorb by downstream method at $5 \mathrm{ml} / \mathrm{min}$ flow rate, and collect $15 \mathrm{ml}$ of the front desorption solution, and the test shows that the concentration of chloride ions is $0.24,0.41$, $0.60 \mathrm{~mol} / \mathrm{L}$ respectively.

It can be seen that the concentration of chloride ions in desorption solution by using the ammonium water was much higher than other desorption solutions. That's because the ammonia water has a multi-effect on neutralizing hydrochloric acid and desorption of hydrochloric acid in the resin. When the concentration of hydrochloric acid in the adsorption solution was $0.13 \mathrm{~mol} / \mathrm{L}$, which less than the desorption solution of ammonia water $(0.27 \mathrm{~mol} / \mathrm{L})$, because the hydrochloric acid in the resin is insufficient for ammonia, and the ammonia water neutralized the hydrochloric acid produced a certain amount of water, so the concentration of chloride ions in the desorption solution was $0.24 \mathrm{~mol} / \mathrm{L}$, which higher than the absorption solution $(0.13 \mathrm{~mol} / \mathrm{L})$, and more or less to the desorption solution $(0.27 \mathrm{~mol} / \mathrm{L})$, When the concentration of hydrochloric acid in the adsorption solution was $0.23 \mathrm{~mol} / \mathrm{L}$, which close to the desorption reagent of ammonia water $(0.27 \mathrm{~mol} / \mathrm{L})$, because the effect of neutralization by ammonia water and water desorption hydrochloric acid, so the concentration of chloride ions in the desorption solution was $0.41 \mathrm{~mol} / \mathrm{L}$, which higher than ammonia water $(0.27 \mathrm{~mol} / \mathrm{L})$ but less than the sum concentration of ammonia water and hydrochloric acid $(0.5 \mathrm{~mol} / \mathrm{L})$. When the concentration of hydrochloric acid in the adsorption solution was $0.36 \mathrm{~mol} / \mathrm{L}$, which higher than ammonia water $(0.27 \mathrm{~mol} / \mathrm{L})$, the effect of neutralization and water desorption had become more obvious, so the concentration of chloride ions in the desorption solution $(0.60 \mathrm{~mol} / \mathrm{L})$ was close to the sum concentration of ammonia water and hydrochloric acid $(0.63 \mathrm{~mol} / \mathrm{L})$. So the result shows that the extremely dilute hydrochloric acid can be enriched and disposed by adsorption with N235 resin and then desorbed with ammonia water.

\section{Conclusions}

1. N235 levextrel resin has a strong adsorption capacity of dilute hydrochloric acid, the adsorption equilibrium coefficient $\mathrm{k}=10^{4}$, the adsorption capacity increases along with the increase of the acidity of the adsorbed liquid and the concentration of chloride ion, decreases along with the flow rate, and increases along with the column height to diameter ratio grow, while the downstream/upstream flow method has little influence on the adsorption capacity.

2. N235 resin receive the maximum concentration of the desorption solution $\mathrm{HCl}$ through adsorption - desorption method of dilute $\mathrm{HCl}$ is equal with the initial concentration of the adsorption solution, which indicated that N235 resin has a "memory effect" on the adsorption-desorption of dilute hydrochloric acid, even change the column diameter ratio can not achieve the purpose of concentration the hydrochloric acid.

3. The adsorption capacity of resin usually exists two platforms. When the initial concentration of $\mathrm{HCl}$ has reached $3.55 \mathrm{~mol} / \mathrm{L}$, the resin adsorption capacity tends to be flatten, reaching 1.42 $\mathrm{mol} / \mathrm{Kg}$. When the initial concentration of $\mathrm{HCl}$ has reached $6.126 \mathrm{~mol} / \mathrm{L}$, the adsorption capacity of resin tends be flatten for the second time, reaching $2.84 \mathrm{~mol} / \mathrm{Kg}$.

4. The extremely dilute hydrochloric acid, which produced in the extraction process of rare earth can be enriched and disposed by adsorption with N235 resin and then desorbed with ammonia water. And this research can be used for the no saponification extraction separation process of rare earth. 


\section{Acknowledgements}

This work was financially supported by the Ministry of science and technology of China "863" plan (2012AA061901). Thanks for the data support from the center for analysis and testing at Jiangxi University of Science and Technology.

\section{Reference}

[1] Li Y X, Zhou X M, Liu Y Z, et al.Development of High Efficiency Extraction and Separation Technologies of Rare Earths from Ion-Adsorbed Type Deposit[J]. Journal of the Chinese Rare Earth Society, 2012, 30(3):257-264.

[2] Li J N , Huang X W, Zhu Z W ,et al.Extracting Rare Earth from D2EHPA-HEHEHP-H $\mathrm{SO}_{4}$ System[J]. Journal of the Chinese Rare Earth Society, 2007, 25(1):55-58.

[3] Zhang Y Q, Li J N , Huang X W, et al. Synergistic Extraction of Rare Earths by Mixture of Di-( 2-ethylhexyl)Phosphoric Acid ( HDEHP)and 2-Ethylhexyl Phosphoric Acid

Mono-2-Ethylhexyl Ester ( HEH EHP)in Sulfuric Acid Medium[J]. Journal of the Chinese Rare Earth Society, 2008, 26(6):671-676.

[4] Huang X W, Li H W, Long Z Q, et al. A process for pretreating organic extractants and its product and application [P].China Patent:200710187954, 2007.

[5] Wang X L, Peng S . Tm ${ }^{3+}$ Extraction Mechanism for HEHEHP-HCl-NaAc System[J]. Journal of the Chinese Rare Earth Society, 2015, 33(2):196-200.

[6] Yang Y M, Lan Q F, Deng S H, et al. Chemical Stability of P507-N235 System and Its Synergistic Extraction for $\mathrm{NdCl}_{3}[\mathrm{~J}]$. Journal of the Chinese Rare Earth Society, 2013, 31(4):385-392.

[7] Yang Y M, Deng S H, Lan Q F, et al.The Rare Earth Extraction and Separation Performance in

[8] Yang Y M, Huang Z H, Deng S H, et al. Recycle of Complex Organic Phase of P507-N235 System[J]. Chinese Journal of Rare Metals, 2014(2):300-305.

P507-N235 System[J]. Nonferrous Metals Science and Engineering, 2013, 4(3):83-86.

[9] Deng S H.The Key Technology of Rare Earth No Saponification Extraction and Separation in P507-N235 system[D].Jiangxi university of science and technology,2012.

[10]Zhang Y . Waste Acid Desorption During Vinyl Chloride Synthesis and Its Application[J].Polyvinyl Chloride, 2006(5):39-40.

[11]Sun A N, Sun G X. Research Progress in Regeneration and Utilization of Waste Hydrochloric Acid[J]. Contemporary Chemical Industry, 2011, 40(11):1178-1181.

[12]Zhao Y L, Wang Y L. Application of Chlorhydric Acid Stripping Process to The Treatment of Waste Acid from The Production of PVC[J]. Polyvinyl Chloride, 2002(6):51-53.

[13]Wang Q ,Sun G X, Sun A N.Study on Reuse of Waste Hydrochloric Acid by Electrolysis[J].Modern Chemical Industry,2011(3):52-54.

[14]Liu R L. A Multiple-Effect Membrane Distillation Process for Deep Concentrating Aqueous Solution of Hydrochloric Acid[D]. Tianjin university, 2012.

[15] Tang J J, Zhou K G. Hydrochloric Acid Recovery from Rare Earth Chloride Solutions by Vacuum Membrane Distillation[J]. Rare Metals, 2006, 25(3):287-292.

[16] Li H C, Zhou Ch SH, Fu B. Solvent Impregnated Resins Technique and Its Application to Hydrometallurgy[J]. Nonferrous Metals, 2001, 53(1):70-73.

[17]Xie Q Y, Chen J, Yang X J, et al. Mechanism of Third-phase Elimination by TBP in N235/HCl Solvent Extraction System[J]. Chinese Journal Of Inorganic Chemistry, 2007,23:57-62

[18]Xie Q Y, Chen J, Yang X J. Effect of HCl Concentration on Formation of Third-phase in $\mathrm{N}_{235}-\mathrm{C}_{12} \mathrm{H}_{26}-\mathrm{HCl}$ Solvent Extraction System[J]. Chinese Journal Of Inorganic Chemistry, 2008, 24(6):897-901. 